\title{
Application of Analog IC Testing Circuit
}

\author{
Ganesh L K M \\ M.Tech Student \\ ECE Dept.,MANIT, \\ Bhopal,India.
}

\author{
Kavita Khare \\ Associated Professor \\ ECE Dept.,MANIT, \\ Bhopal, India.
}

\author{
Priyanka Sharma \\ M.Tech Student \\ ECE Dept.,MANIT, \\ Bhopal,India
}

\begin{abstract}
This paper presents application of Neural classifier with High pass filter(HPF) to examine its own functional health, to speed up test time and to facilitate fault diagnosis Here we presents an application to insert a built in test block to test any complicated analog circuit in terms of performance while considering tolerance factor. Testing block which is to be added in the chip contains Synapse, Common mode canceller and current to voltage converter along with that a simple operational High pass filter ( HPF) is taken as a CUT.
\end{abstract}

\section{Keywords}

Synapse, Neuron, Neural Classifier and Common Mode Canceller.

\section{INTRODUCTION}

The focus of this paper is the neural classifier, which is a component of BIST The neural classifier compares the result of test stimulus and applied stimulus and is classified as a valid or invalid code-word pointing to a functional or faulty operation respectively. With help of very simple HPF as analog circuit to future neural classifier role is described.

\section{HIGH PASS FILTER (HPF)}

A simple HPF (High pass filter) is shown in Fig.1. Fig.2 shows characteristics of two high pass filter which is having same cut of frequency but output voltage slightly various from actual voltage by $+0.6 \mathrm{~V}$ or $-0.6 \mathrm{~V}$. To test analog circuits required circuits considering tolerance factor of +0.6 or -0.6 as no fault. For this neuron based circuits are required which have taken idea from reference paper [1].

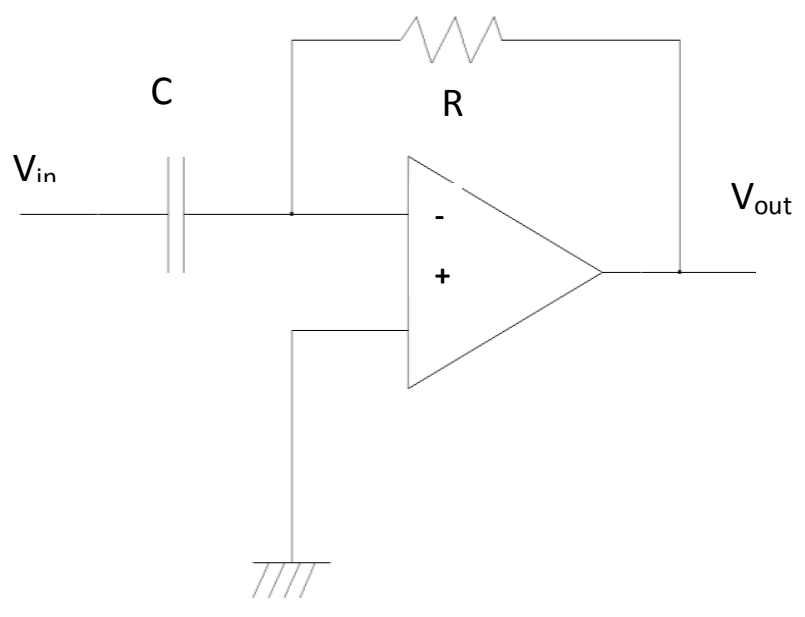

Fig 1: Simple High Pass Filter

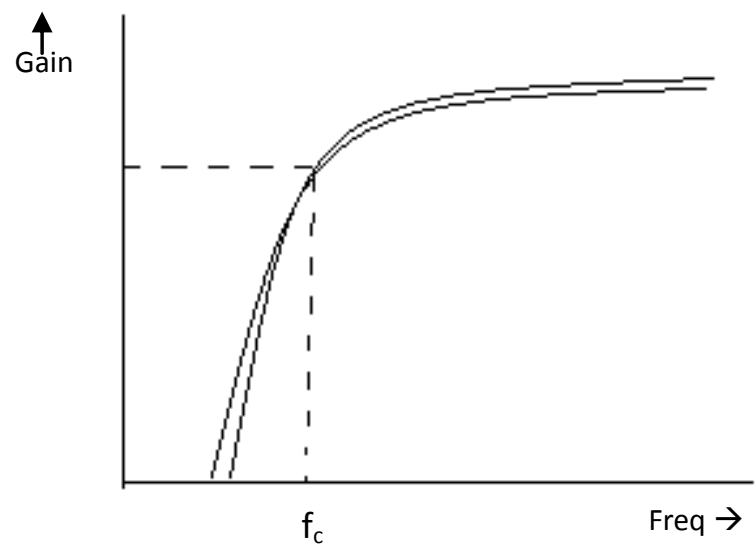

Fig 2: Characteristics of HPF

\section{SYNAPSE CIRCUIT}

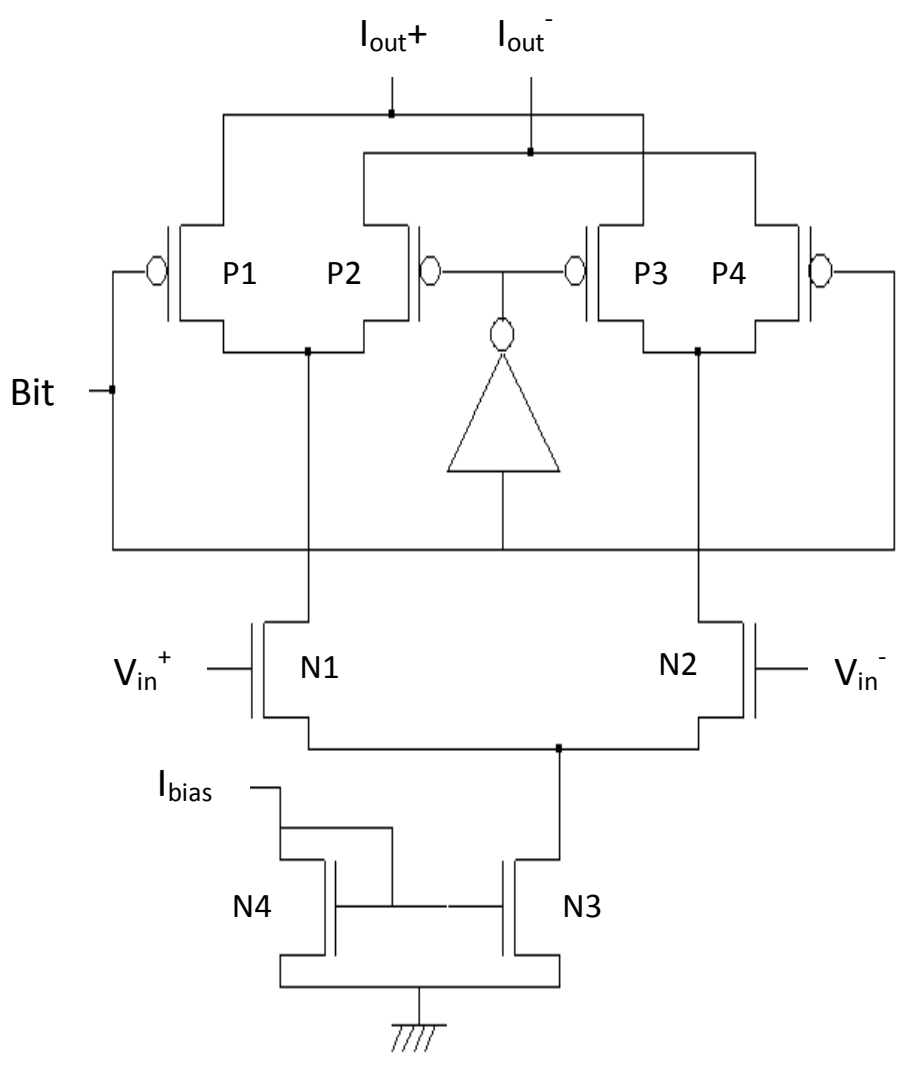

Fig.3: Schematic of the Synapse Circuit 
The basic function of a synapse is multiplication. A synapse circuit[2],[3] is shown in Fig.3.It consists of 4 PMOS and 2 NMOS and takes voltage difference of expected voltage $\left(\mathrm{V}_{\mathrm{IN}}{ }^{+}\right)$and actual voltage $\left(\mathrm{V}_{\mathrm{IN}}{ }^{-}\right)$of output of CUT and provide output in the form of current $\left(\mathrm{I}_{\mathrm{OUT}^{+}}{ }^{+}, \mathrm{I}_{\text {OUT }}{ }^{-}\right)$. To a certain value of input difference voltage $(0.6 \mathrm{~V})$, output current also varies linearly which is called linear multiplication, but if the input voltage difference increased $0.6 \mathrm{~V}$ it gives a constant output current as is clear from the fig. 4.

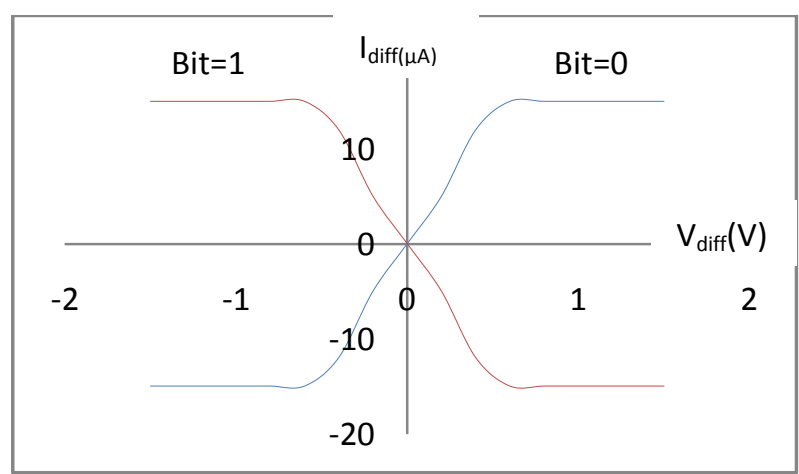

Fig.4: Synapse input voltage diff Vs output current diff

BIT is used to control the characteristics of Synapse. When BIT is low, $\mathrm{P}_{1}$ and $\mathrm{P}_{4}$ will be on resulting $\mathrm{I}_{\mathrm{OUT}}{ }^{+}$and $\mathrm{I}_{\mathrm{OUT}}{ }^{-}$ which are taken from $\mathrm{P}_{1}$ and $\mathrm{P}_{4}$ respectively. Now when BIT is high $\mathrm{P}_{3}$ and $\mathrm{P}_{2}$ will be on resulting $\mathrm{I}_{\mathrm{OUT}}{ }^{+}$and $\mathrm{I}_{\mathrm{OUT}}{ }^{-}$which are taken from $\mathrm{P}_{3}$ and $\mathrm{P}_{2}$ respectively. Hence, inversion in BIT value results in inversion of characteristics, as is clear from Fig.4.

\section{COMMON MODE CANCELLER}

It takes output of Synapse as input and provide output current $\operatorname{MAX}\left(0, \mathrm{I}_{\text {OUT }}{ }^{+}-\mathrm{I}_{\text {OUT }}{ }^{-}\right)$. Common mode canceller is shown in fig. 5. It consists of 4 PMOS and 4 NMOS forming 4 pair of current mirror circuit. As per the concept of current mirror $\mathrm{I}_{\mathrm{IN}}$ and drain current of $\mathrm{P}_{2}$ will be same, which further

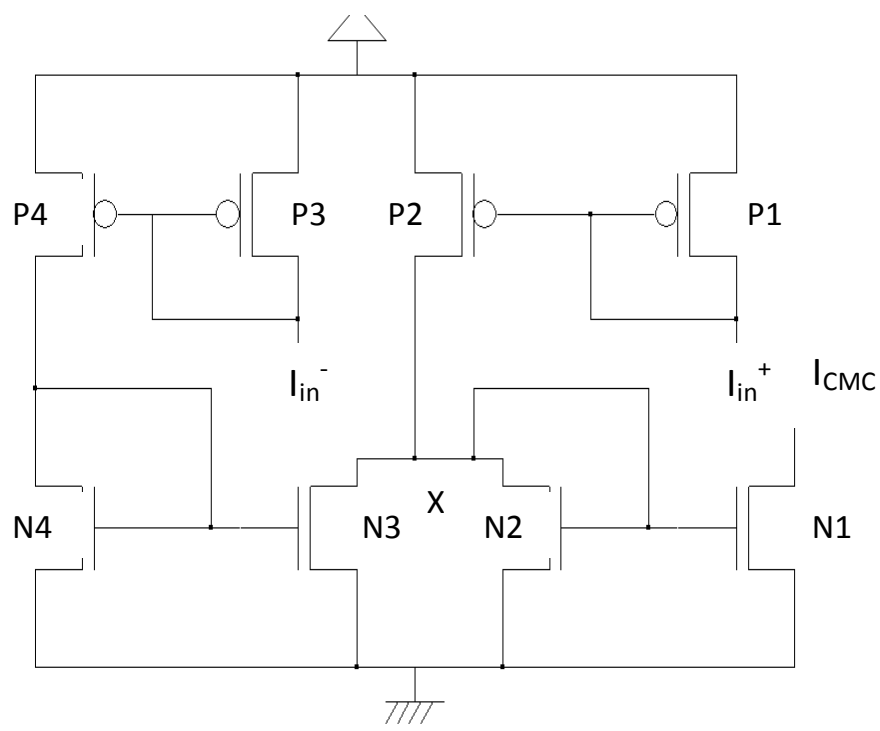

Fig.5: Schematic Common mode canceller be equal to source current of $\mathrm{N}_{2}$ and hence incoming current towards node $\mathrm{X}$. On the other hand $\mathrm{I}_{\mathrm{IN}}{ }^{+}$will be same as drain current of $\mathrm{P}_{3}$ and constituting again outgoing current at node $X$. Difference of $\mathrm{I}_{\mathrm{IN}}{ }^{+}$and $\mathrm{I}_{\mathrm{IN}}{ }^{-}$will be the resultant current of node $\mathrm{X}$ which will further be equal to drain current of $\mathrm{N}_{4}$ and final output $\mathrm{I}_{\mathrm{CMC}}$.

\section{CURRENT TO VOLTAGE \\ CONVERTOR WITH LEVEL SHIFTER}

As name says, $\mathrm{P}_{1}$ and $\mathrm{P}_{2}$ convert current $\left(\mathrm{I}_{\mathrm{CMC}}\right)$ coming from Common Mode Canceller into voltage which further forward to level Shifter formed by $\mathrm{P}_{3}$ and $\mathrm{P}_{4}$. Finally, $\mathrm{V}_{\text {out }}$ which will say about functional health of CUT i.e., Low pass filter. Current to voltage converter with level shifter is shown in Fig.6. It takes $\mathrm{I}_{\mathrm{CMC}}$, i.e. output of Common Mode Canceller as input and gives equivalent voltage at the output end $\left(\mathrm{V}_{\mathrm{OUT}}\right)$.

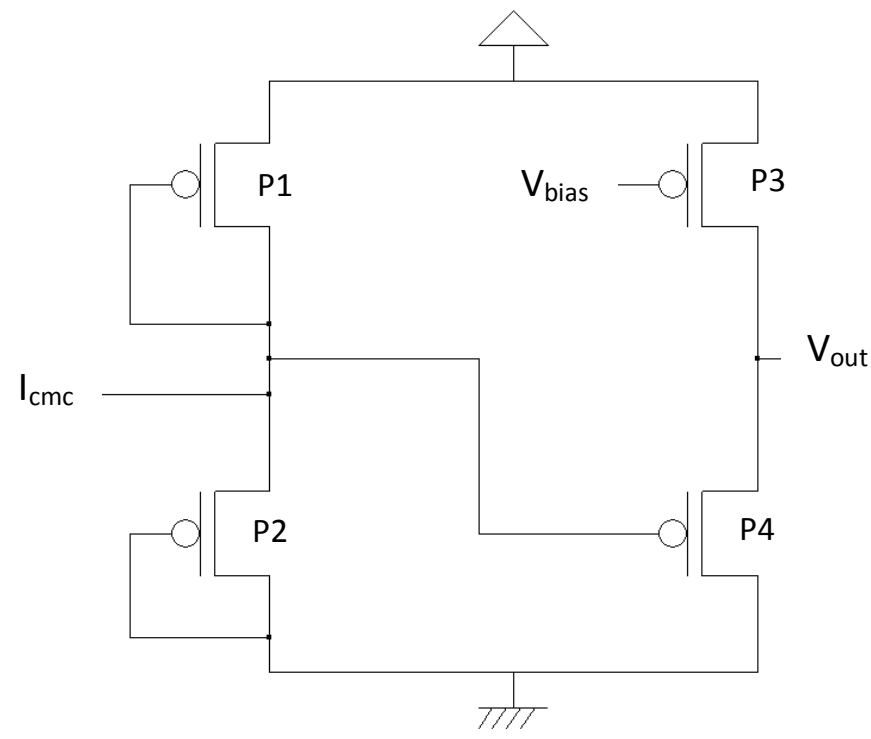

Fig.6: current to voltage converter with level shifter

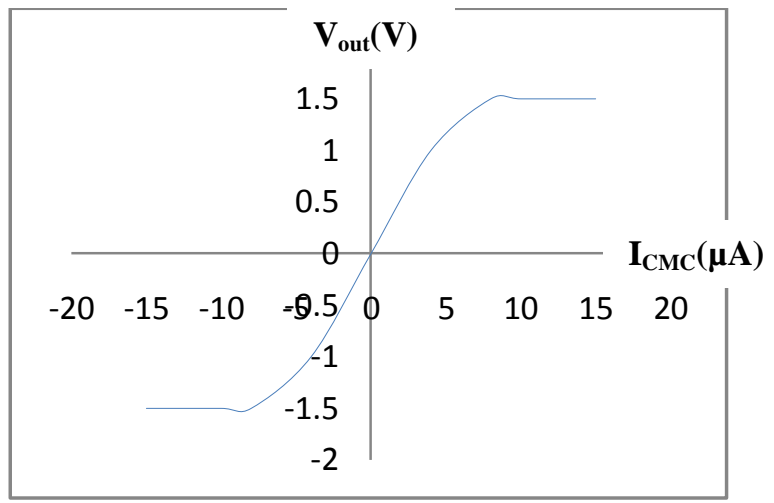

Fig.7: Input current $\left(\mathbf{I}_{\text {сMc }}\right)$ Vs Output voltage $\left(V_{\text {out }}\right)$

\section{HPF WITH TEST BLOCK}

In fig. 8 , When Test Pin is high, MUX produce test stimulus to High pass filter. Their corresponding output is applied to the Synapse for comparison with actual value which is further forward to common mode canceller. Output current $\left(\mathrm{I}_{\mathrm{CMC}}\right)$ is converted into voltage with Current to Voltage converter with Level Shifter. 


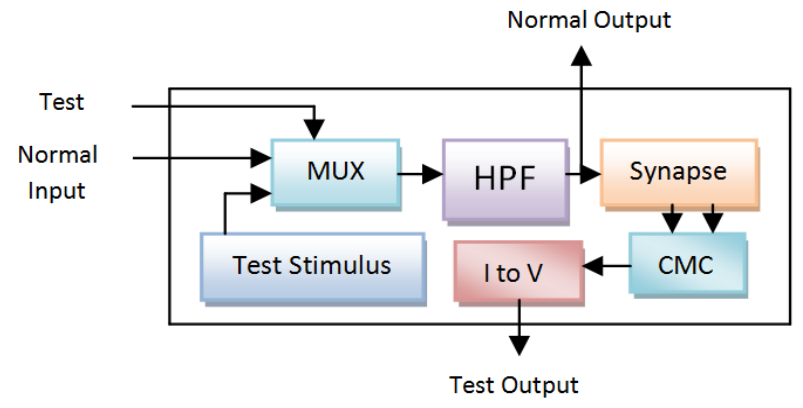

Fig.8. Block Diagram of TEST BLOCK

\section{REUSLT}

By applying different voltages to synapse circuit, outputs observed in all circuits are shown in Table.II and corresponding waveforms are shown in fig.9.

Table 1. Outputs of each stage of Test Block

\begin{tabular}{|c|c|c|c|c|c|c|c|}
\hline Bit & $\mathbf{V}_{\text {in }}^{+}$ & $V_{\text {in }}^{-}$ & $\begin{array}{l}\mathbf{V}_{\text {in }}^{+}- \\
\mathbf{V}_{\text {in }}^{-}\end{array}$ & $\begin{array}{c}\mathbf{I}_{\text {out }}^{+}- \\
\mathbf{I}_{\text {out }}\end{array}$ & $\begin{array}{c}\mathbf{I}_{\text {cmc }} \\
\operatorname{Max}(0, \\
\mathbf{I}_{\text {out }}^{+}{ }^{+} \\
\left.\mathbf{I}_{\text {out }}\right)\end{array}$ & $V_{\text {out }}$ & Result \\
\hline 0 & $1 \mathrm{~V}$ & $1 \mathrm{~V}$ & $0 \mathrm{~V}$ & $0 \mu \mathrm{A}$ & $0 \mu \mathrm{A}$ & 0 & \multirow[t]{2}{*}{ Pass } \\
\hline 1 & $1 \mathrm{~V}$ & $1 \mathrm{~V}$ & $0 \mathrm{~V}$ & $0 \mu \mathrm{A}$ & $0 \mu \mathrm{A}$ & 0 & \\
\hline 0 & $\begin{array}{l}1.2 \\
\mathrm{~V}\end{array}$ & $1 \mathrm{~V}$ & $0.2 \mathrm{~V}$ & $5 \mu \mathrm{A}$ & $5 \mu \mathrm{A}$ & 1.1 & \multirow[t]{2}{*}{$\begin{array}{l}\text { Pass } \\
\text { Pass }\end{array}$} \\
\hline 1 & $\begin{array}{c}1.2 \\
\mathrm{~V}\end{array}$ & $1 \mathrm{~V}$ & $0.2 \mathrm{~V}$ & $5 \mu \mathrm{A}$ & $0 \mu \mathrm{A}$ & 0 & \\
\hline 0 & $1 \mathrm{~V}$ & $\begin{array}{l}1.3 \\
\mathrm{~V}\end{array}$ & $\overline{-}$ & $-7 \mu \mathrm{A}$ & $0 \mu \mathrm{A}$ & 0 & \multirow[t]{2}{*}{ Pass } \\
\hline 1 & $1 \mathrm{~V}$ & $\begin{array}{l}1.3 \\
\mathrm{~V}\end{array}$ & $\overline{-}$ & $7 \mu \mathrm{A}$ & $7 \mu \mathrm{A}$ & 1.3 & \\
\hline 0 & $\begin{array}{l}1.7 \\
V\end{array}$ & $1 \mathrm{~V}$ & 0.7 & $15 \mu \mathrm{A}$ & $15 \mu \mathrm{A}$ & 1.5 & \multirow[t]{2}{*}{ Fail } \\
\hline 1 & $\begin{array}{c}1.7 \\
\mathrm{~V}\end{array}$ & $1 \mathrm{~V}$ & 0.7 & $\begin{array}{c}- \\
15 \mu \mathrm{A}\end{array}$ & $0 \mu \mathrm{A}$ & 0 & \\
\hline 0 & $1 \mathrm{~V}$ & $\begin{array}{c}1.8 \\
\mathrm{~V}\end{array}$ & $\begin{array}{c}- \\
0.8 \mathrm{~V}\end{array}$ & $\begin{array}{c}- \\
15 \mu \mathrm{A}\end{array}$ & $0 \mu \mathrm{A}$ & 0 & \multirow[t]{2}{*}{ Fail } \\
\hline 1 & $1 \mathrm{~V}$ & $\begin{array}{l}1.8 \\
\mathrm{~V}\end{array}$ & $\begin{array}{c}- \\
0.8 \mathrm{~V}\end{array}$ & $15 \mu \mathrm{A}$ & $15 \mu \mathrm{A}$ & 1.5 & \\
\hline
\end{tabular}

\section{CONCLUSION}

Neural classifier which is added to HPF is able to examine its functionality, while considering the tolerance factor. In this way we are able to test any complex analog circuitry at the cost of slight increase in chip area.

Future work will focus on the replacing current mirror with floating gate and its advantages and disadvantages. Constitute of floating gate synapse is an elegant solution for long term nonvolatile memory storage and precise weight updates and local learning.

\section{ACKNOWLEDGMENTS}

It is my proud privilege to express my deep sense of gratitude and sincere thanks towards Dr. Kavita Khare (Associate
Professor, ECE) for her esteem guidance, and valuable suggestions without which it would not have been possible to compile this dissertation work in present form. This work is simply the reflection of her thoughts, ideas, and concepts. I am highly indebted for her kind and valuable suggestions and of course her valuable time during the period of this work. The huge quantum of knowledge I had gained during her inspiring guidance would be immensely beneficial for my future endeavors.

Bit

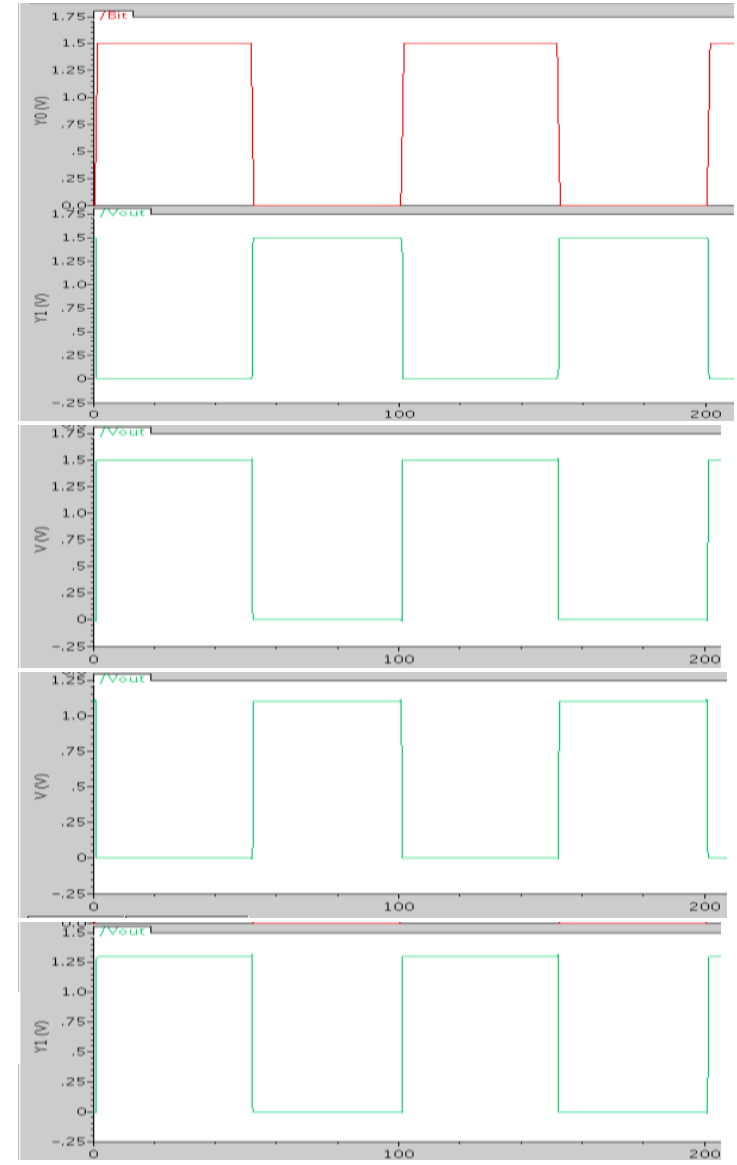

Fig.7 Waveforms for different conditions to Test Block

\section{REFERENCES}

[1] Dzmitry Maliuk , Haralampos-G. Stratigopoulos and Yiorgos Makris" An Analog VLSI Multilayer Perceptron and its Application Towards Built-In Self-Test in Analog Circuits" 2010 IEEE 16th International On-Line Testing Symposium, pp. 71-76, 2010.

[2] V. F. Koosh and R. M. Goodmanr, "Analog VLSI neural network with digital perturbative learning," IEEE Transactions on Circuits and Systems - II, vol. 49, no. 5, pp. 359-368, 2002.

[3] Behzad Razavi, "Design of Analog CMOS Integrated Circuits" published by McGraw-Hill,2001,pp. 104105,2001 